\title{
Developing Rainfall- and Temperature-Based Models to Describe Infection of Canola Under Field Conditions Caused by Pycnidiospores of Leptosphaeria maculans
}

\author{
Kaveh Ghanbarnia, W. G. Dilantha Fernando, and Gary Crow
}

First and second authors: Department of Plant Science; and third author: Department of Animal Science, University of Manitoba, Winnipeg, Manitoba, R3T 2N2 Canada.

Accepted for publication 12 March 2009.

\section{ABSTRACT}

Ghanbarnia, K., Fernando, W. G. D., and Crow, G. 2009. Developing rainfall- and temperature-based models to describe infection of canola under field conditions caused by pycnidiospores of Leptosphaeria maculans. Phytopathology 99:879-886.

Blackleg, also known as Phoma stem canker, caused by Leptosphaeria maculans (Phoma lingam), is one of the most serious diseases of canola worldwide. In this study, the mean disease severity $(D s)$ and incidence (Di) of canola cv. Westar plants infected at the cotyledon, three-leaf, and six-leaf stages by pycnidiospores of $L$. maculans were monitored in the greenhouse after infection of the plants under field conditions in two successive years and associated with meteorological data during infection time. Pearson's correlation coefficient showed that total rainfall per week $(R)$ was significantly correlated to $D s$ on plants infected at the cotyledon, three-leaf, and six-leaf stages, and average maximum temperature per week (Tmax) only showed significant correlation with plants infected at the cotyledon and six-leaf stages. These results also indicated that there is correlation between $D i$ and $R$ for plants infected at all three growth stages. A nonlinear model was developed to evaluate the combined effects of $R$ and Tmax on Ds. The best model comprised monomolecular function and $\beta$ probability density function for plants infected at the above three growth stages. Parameters, including maximum potential for $D s$ at a given rainfall $\left(d_{\max }\right)$, rate of changes with respect to rainfall $(k)$, constant of integration $(B)$, maximum potential for $D s$ with respect to $\operatorname{Tmax}(e)$, rate of increase with increasing Tmax to optimum (n), and rate of decrease as
Tmax increased and passed the optimum $\operatorname{Tmax}(p)$, were estimated for plants infected at the above three growth stages. The effect of plant growth stage was characterized by differences in the upper limit parameter $a$. This parameter was greater for the plants infected at the cotyledon stage than for plants infected at the other two stages. The estimate of parameter $k$ was the same for the plants infected at the cotyledon and three-leaf stages. This parameter was much lower for the plants infected at the six-leaf stage compared with two other stages. The logistic model could describe the disease incidence with respect to $R$ slightly better than the other two models in the plants infected at all three growth stages. Based on the model, upper-limit estimate $\left(d_{\max }\right)$ was $\approx 100,94.4$, and $88.8 \%$ in the plants infected at cotyledon, three-leaf, and six-leaf stages, respectively. $D i$ increased until rainfall reached $\approx 18,10$, and $13 \mathrm{~mm} /$ week and became constant in the plants at cotyledon, three-leaf, and six-leaf stages, respectively. Effects of plant growth stage on the rate of change with respect to $R$ (parameter $k$ ) were lower in the plants infected at cotyledon than at the other two stages. The accuracy of the nonlinear models suggests that they could be used to develop a comprehensive model to evaluate epidemics of blackleg based on pycnidiospores as sources of inoculum. However, additional years of data collection should improve model fit and evaluation of introduced models and contribute to the development of a more robust predictive model.

Additional keywords: Brassica napus.
Blackleg, caused by Leptosphaeria maculans (Desm.) Ces \& De Not (anamorph: Phoma lingam (Tode) Desm.), is one the most serious diseases of canola worldwide $(10,41)$. The pathogen overwinters on crop residue in the form of pseudothecia $(3,41)$ or pycnidia and mycelia (14). In the spring, ascospores or pycnidiospores are discharged and act as primary inoculum in western Canada $(14,41)$. When cotyledons or rosette leaves are infected by aggressive strains, the pathogen spreads systemically from leaf lesions down through the petiole to the stem. In severely infected plants, cankers appear on the stem base and completely girdle the stem during pod filling and are the main reason for yield reductions (3). Severity and incidence of Phoma stem canker depends on many factors, such as survival of inoculum, maturation of fruiting bodies, timing of ascospore release, infection conditions, host growth stage, and host resistance $(14,15,18,21,22,26,27$,

Corresponding author: W. G. D. Fernando;

E-mail address: D_Fernando@umanitoba.ca

* The $\boldsymbol{e}$-Xtra logo stands for "electronic extra" and indicates that Figures 1, 2, and 3 appear in color online.

doi:10.1094/PHYTO-99-7-0879

(C) 2009 The American Phytopathological Society
37,41,42). Dispersal, infection, and disease development of $L$. maculans on the canola plants at different growth stages are, in turn, associated with weather variables such as moisture factors (rainfall and relative humidity) and temperature. Rainfall is a major factor triggering pycnidiospore and ascospore release (13, $15,31,34,40,41)$. Petrie (31) showed that the pattern of ascospore release strongly depends on rain events. In a study in western Canada, Guo and Fernando (13) showed that the peak ascospore dispersal occurred several hours after a rainfall $>2 \mathrm{~mm}$ and persisted for 3 days. Rain-splash dispersal of pycnidiospores of $L$. maculans was studied by Travadon et al. (37). They showed that dispersal pattern of pycnidiospores of $L$. maculans produced by simulated rain in controlled conditions matched the spatial dispersal of pycnidiospores. The effect of temperature was studied on rate of germination, length of germ tube, time of inoculation to penetration, and successful infection of pycnidiospore and ascospores in this pathosystem $(5,16,17,37-39)$. For example, it was observed that, as the temperature increased from 5 to $20^{\circ} \mathrm{C}$, the percentage of ascospores and pycnidiospores germination, length of germ tube, and rate of germination increased $(16,17)$. Vanniasingham and Gilligan (38) mentioned that the probability of successful inoculation with pycnidiospores increased with in- 
creasing temperature from 10 to $25^{\circ} \mathrm{C}$. The effect of relative humidity on blackleg incidence was examined by Wood and Barbetti (43). They indicated that disease incidence rose from 36 to $98 \%$, after cotyledon inoculation with 1 to 50 ascospores, as the duration of high relative humidity $(100 \%)$ was increased from 0 to $120 \mathrm{~h}$. However, when 50 to $10^{5}$ pycnidiospores were used, the disease incidence was affected very little by duration of high humidity and was 18 to $32 \%$. Guo and Fernando (13) also indicated the importance of relative humidity in the release of ascospores in western Canada.

Effects of weather variables have been studied in the blacklegcanola pathosystem as a basis for predicting disease severity, disease incidence, pseudothecia maturity, and ascospore showers $(12,30,33,34$,$) . For example, in a study in the United Kingdom,$ Gladders and Symonds (12) tried to relate rainfall to stem canker incidence based on stepwise regression. Peres and Poisson (30) used a combination of the date of first spore collection and weather variables (amount of rain, number of rain-days, temperature, and number of hours of relative humidity $>90 \%$ ) to generate a preliminary model to predict the risk of stem canker Salam et al. $(33,34)$ introduced models to predict pseudothecia maturity and ascospore shower in relation to blackleg disease in canola based on temperature and rainfall. To our knowledge, a simple model to describe blackleg severity or incidence of canola plants infected by pycnidiospores of blackleg in relation to the combined effects of rainfall and temperature has not been used in this pathosystem. Application of these kinds of models to empirical data from controlled conditions has been studied on different pathogens $(7,44)$. For example, Carisse et al. (7) used a nonlinear model to study the influence of temperature and wetness duration on infection of strawberry leaves by Mycosphaerella fragariae under controlled conditions. However, reports on fitting field data and interpreting the response have not been published and are novel in the blackleg-canola pathosystem. In this study, two previously introduced equations describing disease severity of different pathogens as a function of temperature $(6,9,25,28,44)$ were incorporated into general disease progress models such as monomolecular, logistic, and Gompertz $(6,25)$ to produce an equation to evaluate the combined effects of moisture and temperature factors on Phoma stem canker severity and incidence. Therefore, the objectives of this study were to (i) develop a nonlinear model to describe mean blackleg severity based on combined effects of moisture factors and temperature and (ii) introduce a weatherbased model to describe disease incidence.

\section{MATERIALS AND METHODS}

Field experiment and disease assessment. A 2-year study was conducted to compare the mean blackleg severity and the disease incidence of the canola plants infected under field conditions at three growth stages using Brassica napus cv. Westar. The experiment was carried out in a 50-by-60-m plot from 1 June to 7 July 2004 for 5 weeks and from 27 May to 10 August 2005 for 10 weeks at the Carman Research Station, Carman, Manitoba, Canada. Ten plants at cotyledon (GS 1.0), three-leaf (GS 1, 03), and six-leaf growth stages (GS 1, 06) were each placed in a blackleg-infested canola field for 1 week. The field contained stubble pieces left from blackleg-infected canola plants from previous years. $\mathrm{Cv}$. Westar, susceptible to pathogenicity group 2 (PG2), was used for both years to ensure infection of plants. The plants were then returned to the greenhouse after 1 week and left to grow until maturity. Stem disease severity and incidence ( $D s$ and $D i$, respectively) were evaluated at the pod-filling stage of canola (pods turn yellow). Stem $D s$ was recorded using a 0 -to-5 scale (20). Di was evaluated based on the percentage of infected plants to total plants each week.

Determination of source of inoculum. Three steps were used to determine the source of inoculum in the local area of investigation. In the first approach, blackleg-infected stubble pieces were chosen randomly from the field each week during the experiment in 2004 and 2005 to examine for the presence of pycnidia or pseudothecia using a dissecting microscope $(\times 65$; WILD M3Z, Heerbrugg, Switzerland). The pycnidia and pseudothecia were recognized based on the shape and size of the fruiting body (35). The mean weekly density of fruiting bodies was calculated as described previously (11). In the second step, five rotorod impaction spore samplers (Aerobiology Company, Nepean, Ontario, Canada) were set up in a diagonal orientation within the experimental plot to measure ascospore concentrations based on daily dispersal in the local area. Four rotorod samplers were set up $15 \mathrm{~m}$ from each corner and the last was set up in the middle of the field. The samplers were placed $30 \mathrm{~cm}$ above ground. A CR10 datalogger (Campbell Scientific, Logan, UT) was programmed to operate the rotorods for $5 \mathrm{~min} / \mathrm{h}$. In addition, a 7-day Burkard spore trap (Burkard Scientific Ltd., Uxbridge, Middlesex, UK) was set up in the center of the plot to trap ascospores locally and those probably blown from other areas. Ascospore concentration was measured as previously described (11). Because ascospore showers usually start in the first or second week of June in western Canada $(13,31)$, spore sampling started in the middle of May. Finally, trap plants (all three growth stages) were used in the infested blackleg area to confirm the development of disease.

Data analysis. A generalized randomized complete block design with growth stages (three different stages) of plant as the treatment and week as the block was performed to assess blackleg severity. Ten plants were observed for each growth stage treatment in each week. There were 5 replicate weeks (blocks) in year one and 10 replicate weeks in year two, for 15 replicate weeks in total. Analysis of variance was performed using PC SAS (SAS Institute, Cary, NC) with PROC MIXED. Year, treatment, and their interaction were considered to be fixed effects. Week within year and interaction of treatment with week within year were considered to be random effects. The error term for testing treatment effects is the interaction of treatment and week within year. Square root and arcsine square root transformations were performed for the data of mean $D s$ and $D i$ due to slight departure of the residuals from normality. Means were separated by $t$ test (least significant difference) for the mean $D s$ and $D i$. For $D i$, the percentage of affected plants per 10 plants in each batch was analyzed as in a model similar to that used for blackleg severity but there was only one observation per batch. Also, a randomized complete block design with fruiting bodies (pycnidia and pseudothecia) as treatment and week as the block was performed to compare the presence of main fruiting bodies in the local area. Thirty-five stubble pieces were observed each week. Correlation analysis between weather variables, the total rainfall per week $(R)$, mean temperature per week $(T)$, average minimum and maximum temperature per week (Tmin and Tmax), mean relative humidity per week $(R H)$, average minimum and maximum relative humidity per week (RHmin and RHmax), and mean blackleg severity and incidence was performed using PROC CORR procedure of SAS (version 9.1). Variance inflation factor (VIF) was measured to assess multicollinearity between independent variables. A value of VIF >10 was regarded as multicollinearity. The correlations of the variables with mean $D s$ and $D i$ of blackleg were used as a guide in developing the models. Mean $D s$ and $D i$ data were fit to the models, using the Statistical Analysis System nonlinear regression procedure NLIN with the Guass-Newton method of iteration (version 9.1; SAS Institute). The best model fit was selected based on lower Akaike's Information Criterion (AIC) and mean square error (MSE), higher pseudocoefficient of determination $\left(R^{2}\right)$, as well as a plot of residuals versus predicted values of $D s$ or $D i(6,25)$.

Model development. To develop a model to describe $D s$ and $D i$ based on combined effects of moisture and temperature factors, three steps were performed. In the first step, three nonlinear 
models (Table 1) - monomolecular, logistic (LG), and Gompertzwere selected $(6,9,25,28,29)$ to describe the $D s$ as a function of moisture factors ( $R$ : rainfall or relative humidity). In these equations, upper asymptote, $d_{\max }$ parameter (carrying capacity), corresponds to the maximum potential for $D s$ at given rainfall. Rate parameter $k$ determines how rapidly disease changes with respect to rainfall and parameter $B$ is a constant of integration. In the second step, two models based on the exponential probability density function and the $\beta$ probability density function (Table 2 ), to describe the dependent variable $(D s)$ as a function of temperature $(T)$, were selected $(6,9,28,44)$. In this study, mean temperature per week, average maximum temperature per week, or average minimum temperature per week were considered as temperature factor $(T)$. In these two equations, the parameter $a$ characterizes the maximum potential for $D s$ with respect to $T$. The parameters $m$ and $g$ characterize the intrinsic rate of change and the optimal temperature $D s$ with respect to $T$, respectively. Parameter $n$ describes how steeply $D s$ increases with increasing $T$ up to optimum and the parameter $p$ describes how steeply $D s$ decreases as $T$ increases past the optimum. Parameter $t=\left(T-T_{\min }\right) /\left(T_{\max }-T_{\min }\right)$.

Temperature influences the maximum potential for mean $D s$ $\left(d_{\max }\right)$ at a given moisture factor (9). The effect of temperature could be characterized by allowing parameter $d_{\max }$ to vary with temperature. Therefore, the third and final step, which involved describing $D s$ as a function of $R$ and $T, D s=f(R, T)$, can be performed by a modified version of equations in Table 1 in which $d_{\max }$ is a function of $T(1,7,9,44)$. Substituting $d_{\max }$ in equations in Table 1 gives

$$
\begin{aligned}
& D s=f(R, T)=f(T)[1-B \exp (-k R)] \\
& D s=f(R, T)=f(T) /\{1+B[\exp (-k R)]\} \\
& D s=f(R, T)=f(T)(\exp \{B[\exp (-k R)]\})
\end{aligned}
$$

in which $f(T)$ is calculated by equations in Table 2 . The six final models which describe the $D s$ as a function of $R$ and $T$ can be seen in Table 3 .

\section{RESULTS}

To determine the source of inoculum in the local area of investigation, three approaches were used. In the first, the pycnidia and pseudothecia density on stubble pieces were compared. The results showed that all of them harbored sporebearing pycnidia in each week in 2004 and 2005 (data not shown). In the second method, two different types of spore samplers (Rotorod and Burkard) were used to trap ascospores. No ascospores were detected in most weeks and only very low concentrations of them $\left(0.06\right.$ ascospore $\left./ \mathrm{cm}^{3} / \mathrm{h}\right)$ were observed in weeks one and five in 2005. In the third method, a high level of blackleg incidence and subsequent disease development on the trap plants was observed (Table 4). These findings allowed us to conclude that the disease development on the trap plants could be attributed to the role of pycnidiospores as a main source of inoculum in these years.

Data for the mean $D s$ and $D i$ for the plants infected at cotyledon, three-leaf, and six-leaf stages and weather variables were

TABLE 1. Model expressing mean disease severity $(D s)$ and disease incidence $(D i)$ as a function of moisture factors $(R)^{\mathrm{a}}$

\begin{tabular}{ll}
\hline Model & \multicolumn{1}{c}{ Equation $^{\mathrm{b}}$} \\
\hline Monomolecular & $D s=f(R)=d_{\max }[1-B \exp (-k R)]$ \\
Logistic & $D s=f(R)=d_{\max } /\{1+B[\exp (-k R)]\}$ \\
Gompertz & $D s=f(R)=d_{\max }(\exp \{B[\exp (-k R)]\})$ \\
\hline a Each of these models relates disease incidence or severity to the moisture \\
factors, rainfall or relative humidity $(R)$.
\end{tabular}

summarized in Table 4. Mean Ds was significantly different among the plants infected at the three growth stages (data not shown). However, significant differences in $D i$ were only observed between the plants infected at six-leaf stage and the plants infected at the two other stages. Correlation analysis between $D s$ and $D i$ and the previously mentioned weather variables was performed. The results showed that positive and significant Pearson's correlations existed between the mean $D s$ of blackleg for plants infected at three growth stages and selected weather variables in both years (Tables 5 and 6). In all three canola growth stages, correlations between $D s$ of blackleg and total rainfall per week were significant $(P<0.05)$. The correlation value was $0.62,0.53$, and 0.30 in 2004 and $0.52,0.31$, and 0.49 in 2005 for plants infected at cotyledon, three-leaf, and six-leaf stages, respectively. However, significant correlation between relative humidity $(R H$, RHmin, and RHmax) and mean Ds was only observed in 2005. A negative correlation also was observed between $D s$ and temperature factors (mean temperature and average maximum temperature per week) in the plants infected at cotyledon and six-leaf stages. This correlation was observed in plants infected at threeleaf stage only in 2004. The correlation value between $D s$ and Tmax was higher than $D s$ and $T$ for the two plant growth stages in both years except for the plants infected at cotyledon stage, in where the value was slightly smaller for Tmax than $T(0.49$ to $0.50)$ in 2004. The correlation between the remaining variables and the mean $D s$ were either not significant or there was correlation between them and $R$ (e.g., $R H$ correlated to $R$ in the plants infected at six-leaf stage) (data not shown). Therefore, total rainfall per week $(R)$ and average maximum temperature per week (Tmax) were used as independent variables to describe the mean $D s$ of plants infected at cotyledon and six-leaf stages. Multicollinearity between these two variables was not a cause for concern (VIF between them was $<2$ for the three plant growth stages tested). Tmax did not correlate with $D s$ in the plants infected at three-leaf stage. Nevertheless, the data for Tmax was used to estimate parameters of the final model describing $D s$ for the plants at this growth stage only for comparison with the models introduced for the other two stages.

TABLE 2. Model expressing mean disease severity $(D s)$ as a function of temperature $(T)$

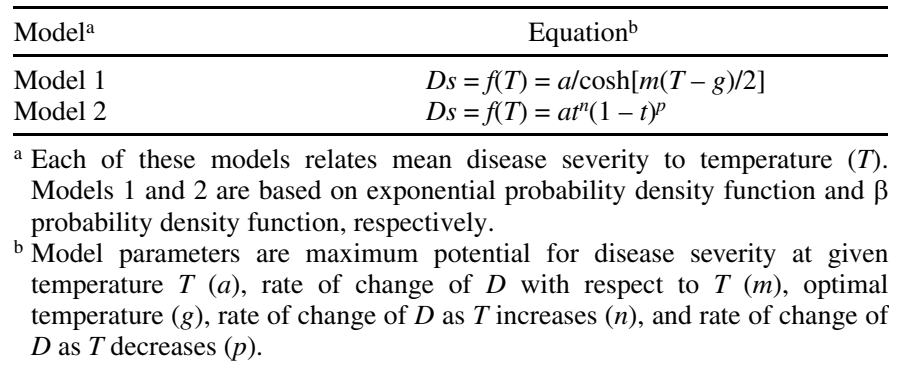

TABLE 3. Models expressing mean disease severity $(D s)$ as a function of moisture factor $(R)$ and temperature $(T)^{\mathrm{a}}$

\begin{tabular}{ll}
\hline Model & \multicolumn{1}{c}{ Equation } \\
\hline 1 & $D s=f(R, T)=a[1-B \exp (-k R)] / \cosh [m(T-g) / 2]$ \\
2 & $D s=f(R, T)=a t^{n}(1-t)^{p}[1-B \exp (-k R)]$ \\
3 & $D s=f(R, T)=a /\{1+B[\exp (-k R)] \cosh [m(T-g) / 2]\}$ \\
4 & $D s=f(R, T)=a t^{n}(1-t)^{p}\{1-B[\exp (-k R)]\}$ \\
5 & $D s=f(R, T)=a /[\exp \{B[\exp (-k R)]\}] \cosh [m(T-g) / 2]$ \\
6 & $D s=f(R, T)=a t^{n}(1-t)^{p}[\exp \{B[\exp (-k R)]\}]$ \\
\hline
\end{tabular}

${ }^{a}$ Model parameters are maximum potential for disease severity at given rainfall $\left(d_{\max }\right)$, constant of integration $(B)$, rate of disease change with respect to increasing moisture factor $(k)$, total rainfall per week $(R)$, maximum potential for disease severity at given temperature $T(a)$, rate of change of $D s$ with respect to $T(m)$, optimal temperature $(g)$, rate of change of $D s$ as $T$ increases $(n)$, and rate of change of $D s$ as $T$ decreases $(p)$. 
Effects of rainfall and temperature on the mean $D s$. The results of nonlinear regression analysis in the SAS program for six mentioned models are summarized in Table 7 . To avoid overparameterization, parameter $B$ for models 1,3 , and 5 was fixed to $0.7,1.9$, and 1.1 , respectively, for the plants infected at cotyledon, three-leaf, and six-leaf stages based on the preliminary regression analysis. To use models 2, 4, and 6, estimates of Tmax min $_{\text {and }}$ and Tmax $_{\max }$ were also needed, which were not known before data collection. Based on Table 1, $\operatorname{Tmax}_{\min }$ was $17.4^{\circ} \mathrm{C}$ and $\operatorname{Tmax}_{\max }$ was $29.2^{\circ} \mathrm{C}$. Therefore, the value of 17 and $29.5^{\circ} \mathrm{C}$ were used as Tmax $_{\min }$ and $\operatorname{Tmax}_{\max }$, respectively. The results indicated that models 2, 4, and 6 described $D$ s better than models 1, 3, and 5 for all three growth stages. The first group had higher $R^{2}$ and lower MSE and AIC (Table 7). The plot of residual versus predicted $D s$ also showed more normal distribution than the latter group and the standard errors of the estimated parameters were lower. Comparison of models 2, 4, and 6 revealed that model 2 is slightly better than models 4 and 6 . Pseudo- $R^{2}$ for models 2,4 , and 6 was almost the same. These values were $0.85,0.84$, and 0.85 for models 2, 4, and 6, respectively, in the plants infected at cotyledon, three-leaf, and six-leaf stage. However, MSE and AIC value was lower in model 2 compared with the other two models. These values were 0.35 and -19.4 for model 2 compared with 0.38 and -18.3 for model 4 and 0.36 and -19.1 for model 6 . Overall, model 2 described the mean $D s$ slightly better compared with models 4 and 6 in the plants infected at cotyledon stage. This model also could express $D s$ better than five other models in the plants infected at three-leaf and six-leaf stages. Therefore, model 2 was selected to describe $D s$ as a function of total rainfall per week $(R)$ and average maximum temperature per week (Tmax) in the plants infected at all three stages. The response surface for this model, $D s=f(R, T)=a t^{n}(1-T)^{p}[1-B \exp (-k R)]$, on the plants infected at cotyledon stage, three-leaf, and six-leaf stages can be seen in Figures 1, 2, and 3, respectively.

Disease resistance was characterized primarily by differences in the upper limit of $D s$ (parameter $a$ ). This parameter was great-

TABLE 4. Mean blackleg severity and incidence of canola plants infected at three different growth stages and weather conditions at Carman Research Centre in Manitoba in 2004 and 2005

\begin{tabular}{|c|c|c|c|c|c|c|c|c|c|c|c|c|c|c|}
\hline Year & Week & DSC & DSL & DSR & DIC & DIL & DIR & $R$ & $T$ & $T_{\text {min }}$ & $T_{\max }$ & $R H$ & $R H_{\text {min }}$ & $R H_{\max }$ \\
\hline 2004 & 1 & 4.2 & 2.9 & 1.8 & 100 & 100 & 80 & 15.0 & 15.0 & 9.9 & 21.0 & 74.0 & 50.1 & 95.3 \\
\hline 2004 & 2 & 2.8 & 1.5 & 1.3 & 77 & 50 & 50 & 3.0 & 13.8 & 8.7 & 19.0 & 79.0 & 59.3 & 98.2 \\
\hline 2004 & 3 & 4.7 & 2.9 & 1.9 & 100 & 100 & 90 & 14.0 & 12.9 & 8.4 & 17.4 & 70.0 & 39.4 & 96.5 \\
\hline 2004 & 4 & 1.2 & 0.7 & 0.4 & 50 & 66 & 22 & 0.0 & 16.4 & 9.7 & 23.0 & 70.0 & 50.5 & 93.4 \\
\hline 2004 & 5 & 2.4 & 1.8 & 1.8 & 80 & 90 & 70 & 3.4 & 15.2 & 10.2 & 20.3 & 85.5 & 68.2 & 94.6 \\
\hline 2005 & 1 & 2.4 & 2.2 & 1.6 & 100 & 100 & 100 & 9.9 & 14.6 & 9.8 & 19.4 & 85.5 & 64.1 & 99.0 \\
\hline 2005 & 2 & 3.6 & 2.6 & 3.4 & 100 & 100 & 100 & 19.8 & 14.5 & 11.1 & 17.9 & 92.3 & 79.1 & 99.6 \\
\hline 2005 & 3 & 3.0 & 2.7 & 2.6 & 100 & 88 & 100 & 32.4 & 16.4 & 12.3 & 20.5 & 93.1 & 77.4 & 100 \\
\hline 2005 & 4 & 1.3 & 0.7 & 0.4 & 70 & 33 & 44 & 0.2 & 22.4 & 15.5 & 29.2 & 77.1 & 55.7 & 96.7 \\
\hline 2005 & 5 & 4.0 & 3.2 & 3.4 & 100 & 100 & 88 & 83.8 & 15.5 & 11.3 & 19.7 & 90.0 & 75.0 & 100 \\
\hline 2005 & 6 & 4.1 & 2.7 & 2.1 & 100 & 90 & 66 & 28.8 & 18.6 & 13.1 & 24.1 & 89.9 & 69.7 & 100 \\
\hline 2005 & 7 & 2.3 & 1.1 & 0.9 & 100 & 75 & 77 & 19.2 & 23.6 & 18.1 & 29.2 & 90.1 & 75.7 & 100 \\
\hline 2005 & 8 & 3.6 & 2.4 & 2.6 & 100 & 100 & 100 & 34.6 & 18.7 & 13.1 & 21.6 & 89.0 & 60.1 & 100 \\
\hline 2005 & 9 & 1.5 & 1.8 & 0.9 & 60 & 55 & 40 & 1.2 & 17.6 & 11.6 & 23.6 & 79.6 & 55.6 & 99.0 \\
\hline 2005 & 10 & 2.0 & 2.4 & 0.7 & 60 & 88 & 60 & 6.4 & 21.0 & 13.6 & 28.4 & 79.8 & 65.6 & 99.1 \\
\hline
\end{tabular}

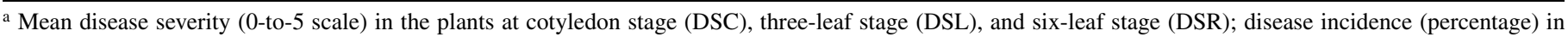
plants at cotyledon stage (DIC), three-leaf stage (DIL), and six-leaf stage (DIR); total rainfall per week $(R)$, mean temperature per week ( $T$ ), average minimum temperature per week $\left(T_{\min }\right)$, average maximum temperature per week $\left(T_{\max }\right)$, mean relative humidity per week $(R H)$, average minimum relative humidity per week $\left(R H_{\min }\right)$, and average maximum relative humidity per week $\left(R H_{\max }\right)$.

TABLE 5. Pearson's correlation coefficient between weather variables and mean disease severity in 2004 and $2005^{\text {a }}$

\begin{tabular}{|c|c|c|c|c|c|c|}
\hline \multirow[b]{2}{*}{ Weather variables } & \multicolumn{3}{|c|}{2004} & \multicolumn{3}{|c|}{2005} \\
\hline & Cotyledon & Three-leaf & Six-leaf & Cotyledon & Three-leaf & Six-leaf \\
\hline Total rainfall & $0.62 * * *$ & $0.53 * * *$ & $0.30^{*}$ & $0.52 * * *$ & $0.31^{*}$ & $0.49 * *$ \\
\hline Mean temperature & $-0.50 * *$ & $-0.32 *$ & -0.25 & -0.25 & -0.24 & $-0.45^{* *}$ \\
\hline Minimum temperature & $-0.29 *$ & -0.11 & -0.01 & -0.14 & -0.19 & $-0.31 *$ \\
\hline Maximum temperature & $-0.49 * *$ & $-0.33^{*}$ & $-0.27^{*}$ & $-0.33 * *$ & -0.25 & $-0.55 * * *$ \\
\hline Mean $R H^{\mathrm{b}}$ & -0.14 & -0.11 & 0.15 & $0.50 * * *$ & $0.32 *$ & $0.54 * * *$ \\
\hline Minimum $R H$ & $-0.34 *$ & -0.26 & 0.01 & $0.36 * *$ & $0.21 *$ & $0.44^{* *}$ \\
\hline Maximum $R H$ & 0.09 & 0.09 & 0.24 & $0.43 * * *$ & $0.38 *$ & $0.39 * *$ \\
\hline
\end{tabular}

a Values followed by $*$, **, and $* * *$ are significant at $0.01,0.001$, and 0.0001 , respectively.

${ }^{\mathrm{b}} \mathrm{RH}=$ mean relative humidity per week.

TABLE 6. Pearson's correlation coefficient between weather variables and disease incidence in 2004 and $2005^{\mathrm{a}}$

\begin{tabular}{|c|c|c|c|c|c|c|}
\hline \multirow[b]{2}{*}{ Weather variables } & \multicolumn{3}{|c|}{2004} & \multicolumn{3}{|c|}{2005} \\
\hline & Cotyledon & Three-leaf & Six-leaf & Cotyledon & Three-leaf & Six-leaf \\
\hline Total rainfall per week & $0.78 *$ & $0.79 *$ & $0.91 * *$ & $0.79 *$ & $0.65^{*}$ & $0.68 *$ \\
\hline Mean temperature per week & -0.17 & -0.63 & -0.60 & -0.35 & -0.56 & -0.56 \\
\hline Minimum temperature per week & 0.21 & -0.11 & -0.25 & -0.77 & -0.45 & -0.34 \\
\hline Maximum temperature per week & -0.22 & -0.58 & -0.59 & -0.53 & -0.64 & -0.71 \\
\hline Mean $R H^{\mathrm{b}}$ & -0.11 & -0.19 & 0.02 & $0.89 *$ & $0.69 *$ & $0.80 * *$ \\
\hline Minimum $R H$ per week & -0.34 & -0.15 & 0.31 & $0.80 *$ & 0.42 & 0.62 \\
\hline Maximum $R H$ per week & -0.005 & 0.47 & 0.31 & 0.59 & $0.77 *$ & 0.58 \\
\hline
\end{tabular}

a Values followed by $*$ and $* *$ are significant at 0.01 and 0.001 , respectively.

${ }^{\mathrm{b}} \mathrm{RH}=$ mean relative humidity per week. 
est in plants at the cotyledon stage $(a=4.29)$ compared with three-leaf $(a=2.77)$ and six-leaf $(a=2.65)$ stages. Effects of plant growth stage on the rate of change of $D s$ with respect to $R$ (parameter $k$ ) were 0.2 and 0.24 for plants infected at cotyledon and three-leaf stages, respectively. However, this rate was less (0.04) for plants infected at the six-leaf stage compared with the plants at the two other stages (Table 7; Figs. 1 to 3), which implies that $D s$ was increasing with lower slope with respect to $R$ in this growth stage. These results also showed that the value of parameter $p$ was significantly smaller for plants at the three-leaf stage ( $p=0.03)$ compared with plants at the cotyledon and sixleaf stages. This was (as expected) due to lack of correlation of $D s$ with average maximum temperature in the plant at three-leaf stage. The value for parameter $p$ was almost the same for plants at the cotyledon $(p=0.16)$ and six-leaf stage $(p=0.17)$, which means that $D s$ for plants in both growth stages decreases with the same slope after it passes the optimum temperature.

Effects of rainfall and temperature on $\mathrm{Di}$. Positive and significant correlation was also observed between total rainfall per week and blackleg incidence in the plants infected in all three growth stages (Table 6). These correlations were $0.78,0.79$, and 0.91 in 2004 and $0.79,0.65$, and 0.68 in 2005 for the plants infected at cotyledon, three-leaf, and six-leaf stages, respectively. The correlations between the remaining variables and $D i$ were either not significant or not reproducible (e.g., mean $R H$ per week correlated to $\mathrm{Di}$ only in 2005). Therefore, only total rainfall per week was used for model development among all weather variables. The results of nonlinear regression of the three mentioned models to describe the blackleg incidence in the plants infected at three growth stages are summarized in Table 8. These results showed that the LG model could describe the $D i$ slightly better than the other two models in plants infected at all three growth stages. The pseudo- $R^{2}$ was higher and AIC and MSE were smaller for the LG model compared with the other two. The nonlinear regression analysis showed that the LG model could explain 80, 70 , and $77 \%$ of blackleg incidence variation in the plants infected at cotyledon, three-leaf, and six-leaf stages, respectively. The blackleg incidence increased with increasing rainfall, then became constant (Fig. 4). Di increased until rainfall reached $\approx 18,10$, and $13 \mathrm{~mm}$ and became constant in the plants at cotyledon, three-leaf, and six-leaf stages, respectively. Upper limit of $D i\left(d_{\max }\right)$ was higher in the plants infected at cotyledon stage than in the plants infected at the other two stages. Effects of plant growth stage on the rate of change with respect to $R$ (parameter $k$ ) were lower in the plants infected at cotyledon stage than in the plants infected at the other two stages. This value was $\approx 0.18,0.37$, and 0.35 for the plants infected at cotyledon, three-leaf, and six-leaf stages, respectively.

\section{DISCUSSION}

The effects of total rainfall per week $(R)$ and average maximum temperature (Tmax) on the mean $D s$ of plants infected at three

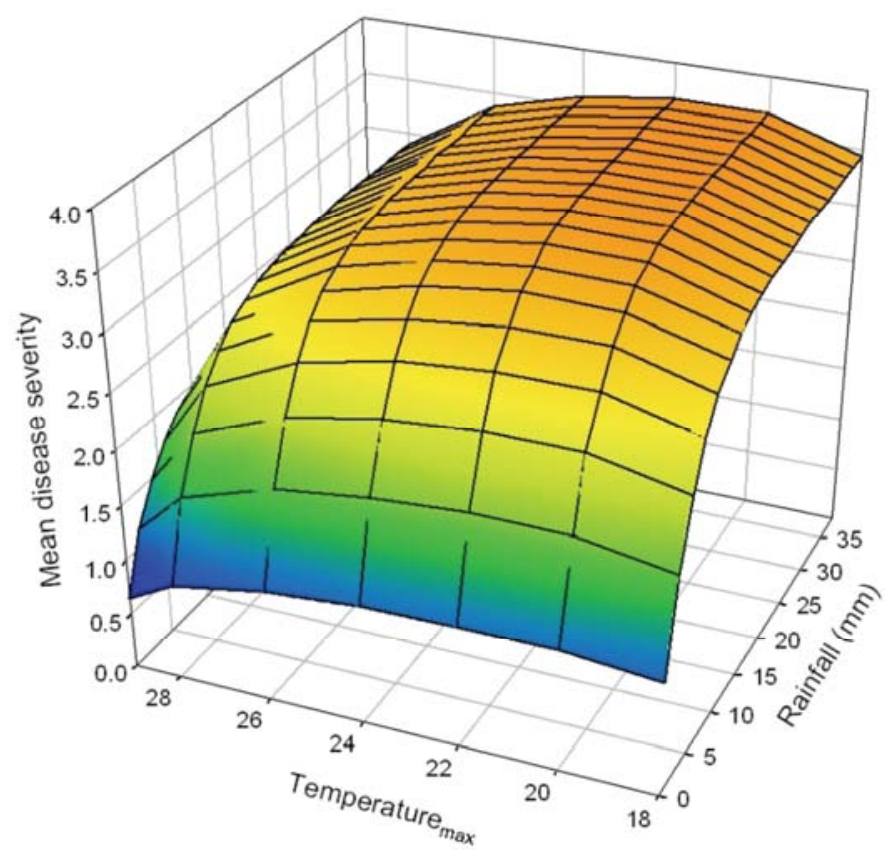

Fig. 1. Response surface for model 2 , disease severity $(D s)=4.29 t^{0.07}(1-$ $t)^{0.16} \cdot\{1-[0.7 \exp (-0.2 R)]\}$, describing the influence of total rainfall per week $(R)$ and average maximum temperature per week $\left(T_{\max }\right)$ on the mean blackleg severity of the canola plants infected at cotyledon stage.

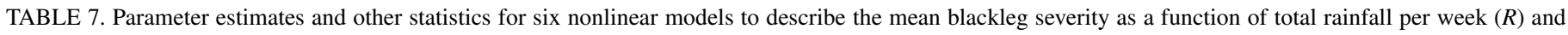
average maximum temperature per week (Tmax) in canola cv. Westar ${ }^{a}$

\begin{tabular}{|c|c|c|c|c|c|c|c|c|c|c|}
\hline \multirow[b]{2}{*}{ Model } & \multirow[b]{2}{*}{$\mathrm{GS}^{\mathrm{b}}$} & \multirow[b]{2}{*}{ MSE } & \multirow[b]{2}{*}{$R^{2}$} & \multirow[b]{2}{*}{ AIC } & \multicolumn{6}{|c|}{ Estimated parameters ${ }^{c}$} \\
\hline & & & & & $a$ & $n$ & $p$ & $k$ & $m$ & $g$ \\
\hline \multirow[t]{3}{*}{1} & 1,0 & 0.41 & 0.72 & -11.7 & $\ldots$ & $\ldots$ & $\ldots$ & $0.25(0.11)$ & $0.16(0.12)$ & $18.75(6.4)$ \\
\hline & 1,03 & 0.19 & 0.69 & -22.3 & $\ldots$ & $\ldots$ & $\ldots$ & $0.40(0.17)$ & $0.17(0.10)$ & $20.31(4.1)$ \\
\hline & 1,06 & 0.16 & 0.83 & -24.9 & $\ldots$ & $\ldots$ & $\ldots$ & $0.12(0.04)$ & $0.29(0.10)$ & $18.67(2.2)$ \\
\hline \multirow[t]{3}{*}{2} & 1,0 & 0.35 & 0.85 & -19.4 & $4.29(0.91)$ & $0.07(0.11)$ & $0.16(0.15)$ & $0.20(0.09)$ & $\ldots$ & $\ldots$ \\
\hline & 1,03 & 0.08 & 0.92 & -40.3 & $2.77(0.35)$ & $-0.01(0.07)$ & $0.03(0.06)$ & $0.24(0.07)$ & $\ldots$ & $\ldots$ \\
\hline & 1,06 & 0.08 & 0.95 & -40.1 & $2.65(0.64)$ & $-0.19(0.07)$ & $0.17(0.17)$ & $0.04(0.03)$ & $\ldots$ & $\ldots$ \\
\hline \multirow[t]{3}{*}{3} & 1,0 & 0.41 & 0.72 & -11.6 & $\ldots$ & $\ldots$ & $\ldots$ & $0.39(0.15)$ & $0.16(0.12)$ & $18.78(6.1)$ \\
\hline & 1,03 & 0.19 & 0.68 & -22.1 & $\ldots$ & $\ldots$ & $\ldots$ & $0.59(0.21)$ & $0.17(0.10)$ & $20.27(4.1)$ \\
\hline & 1,06 & 0.18 & 0.81 & -23.5 & $\ldots$ & $\ldots$ & $\ldots$ & $0.19(0.06)$ & $0.29(0.11)$ & $18.87(2.3)$ \\
\hline \multirow[t]{3}{*}{4} & 1,0 & 0.38 & 0.84 & -18.3 & $4.26(0.92)$ & $0.07(0.11)$ & $0.15(0.16)$ & $0.30(0.13)$ & $\ldots$ & $\ldots$ \\
\hline & 1,03 & 0.09 & 0.91 & -38.6 & $2.76(0.37)$ & $-0.006(0.08)$ & $0.03(0.07)$ & $0.39(0.11)$ & $\ldots$ & $\ldots$ \\
\hline & 1,06 & 0.08 & 0.95 & -40.1 & $2.39(0.47)$ & $-0.20(0.08)$ & $0.17(0.18)$ & $0.08(0.04)$ & $\ldots$ & $\ldots$ \\
\hline \multirow[t]{3}{*}{5} & 1,0 & 0.41 & 0.72 & -11.8 & $\ldots$ & $\ldots$ & $\ldots$ & $0.32(0.13)$ & $0.16(0.12)$ & $18.78(6.2)$ \\
\hline & 1,03 & 0.19 & 0.69 & -22.2 & $\ldots$ & $\ldots$ & $\ldots$ & $0.48(0.19)$ & $0.17(0.10)$ & $20.29(4.1)$ \\
\hline & 1,06 & 0.17 & 0.82 & -23.9 & $\ldots$ & $\ldots$ & $\ldots$ & $0.15(0.05)$ & $0.28(0.10)$ & $18.82(2.3)$ \\
\hline \multirow[t]{3}{*}{6} & 1,0 & 0.36 & 0.85 & -19.1 & $4.26(0.90)$ & $0.07(0.10)$ & $0.16(0.16)$ & $0.25(0.11)$ & $\ldots$ & $\ldots$ \\
\hline & 1,03 & 0.08 & 0.92 & -39.6 & $2.76(0.35)$ & $-0.01(0.08)$ & $0.03(0.06)$ & $0.30(0.09)$ & $\ldots$ & $\ldots$ \\
\hline & 1,06 & 0.08 & 0.94 & -39.6 & $2.45(0.52)$ & $-0.19(0.07)$ & $0.17(0.17)$ & $0.06(0.04)$ & $\ldots$ & $\ldots$ \\
\hline
\end{tabular}

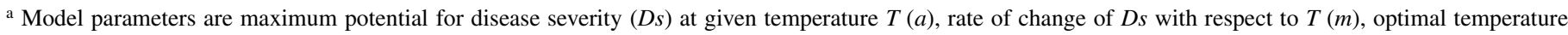
$(\mathrm{g})$, rate of change of $D s$ as $T$ increases $(n)$, rate of change of $D s$ as $T$ decreases $(p)$, and rate of disease change with respect to increasing moisture factor $(k)$. Mean square error (MSE), pseudo-coefficient of determination $\left(R^{2}\right)$, and Akaike's Information Criterion (AIC) are presented for each model.

${ }^{\mathrm{b}}$ Growth stages: cotyledon stage $(1,0)$, three-leaf stage $(1,03)$, and six-leaf stage $(1,06)$.

c Numbers in parentheses correspond to the standard error. 


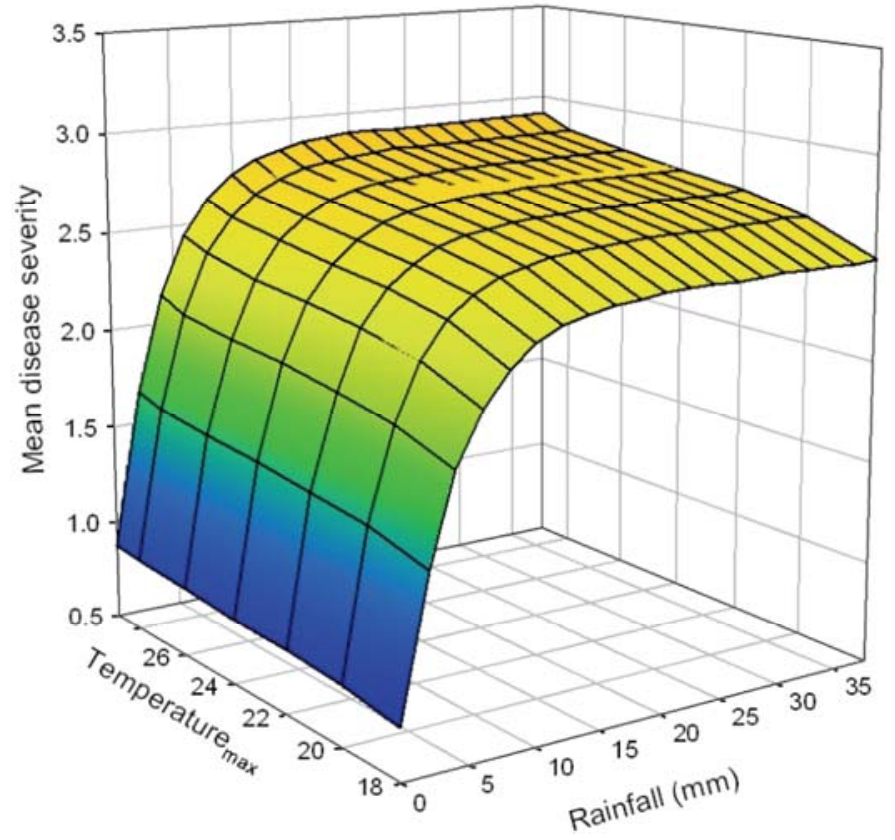

Fig. 2. Response surface for model 2 , disease severity $(D s)=2.77 t^{0.03}(1-$ $t)^{-0.01} \cdot\{1-[0.7 \exp (-0.24 R)]\}$, describing the influence of total rainfall per week $(R)$ and average maximum temperature per week $\left(T_{\max }\right)$ on the mean blackleg severity of the canola plants infected at three-leaf stage.

growth stages of B. napus cv. Westar were defined. To describe $D s$ as a function of $R$, three known models (monomolecular, LG, and Gompertz) were employed. Weibull and Richards models are more flexible than the three above models used in this study due to their shape parameter, which can accommodate a wide variety of disease. However, using models with a higher number of parameters when the sample sizes are small causes inaccuracy in the parameter estimation or overparameterization. The accuracy of the introduced model for describing $D s$ in the plants infected at cotyledon, three-leaf, and six-leaf stages based on the combined effects of the two above variables was high. Because pseudo-coefficient of determination $\left(R^{2}\right)$ value is not always reliable in estimating goodness-of-fit for nonlinear models (25), other statistics such as AIC, MSE, and plots of residuals and estimates intervals were used. Reasonable estimates of parameters and their standard errors were also considered to choose appropriate models. Based on these five criteria, the results indicated that a significant proportion of variability in $D s$ was accounted for by the independent variables of $R$ and Tmax. The mean $D s$ of plants infected at all three growth stages increased with increase in the total rainfall per week. At rainfall values totaling $>15 \mathrm{~mm} /$ week, $D s$ became constant in the plants infected at cotyledon and three-leaf stages. Unlike the above two growth stages, $D s$ increased exponentially when $R$ exceeded $15 \mathrm{~mm}$ in plants infected at the six-leaf stage. However, the rate of increase of $D s$ with respect to $R$ (parameter $k$ ) is much less than in plants infected at the two other stages (this value is 0.04 for plants infected at the six-leaf stage compared with 0.2 and 0.24 for plants infected at the cotyledon and threeleaf stages, respectively). Increasing mean $D s$ with increasing precipitation can be attributed to increase in splash dispersal of pycnidiospores $(14,37,42,43)$. The correlation between pycnidiospores dispersal and rainfall events has been observed in other pathogens producing rain-splashed spores $(2,3)$. However, the constant level of mean $D s$ whenever total rainfall per week exceeded $15 \mathrm{~mm}$ may be due to spore removal from the source (pycnidia) and spore wash-off from infection sites and shaking caused by the impact of the drops $(8,21,24)$. It was also shown that germination of pycnidiospores of L. maculans under controlled conditions was strongly inhibited by a high density of the spore suspension (38).

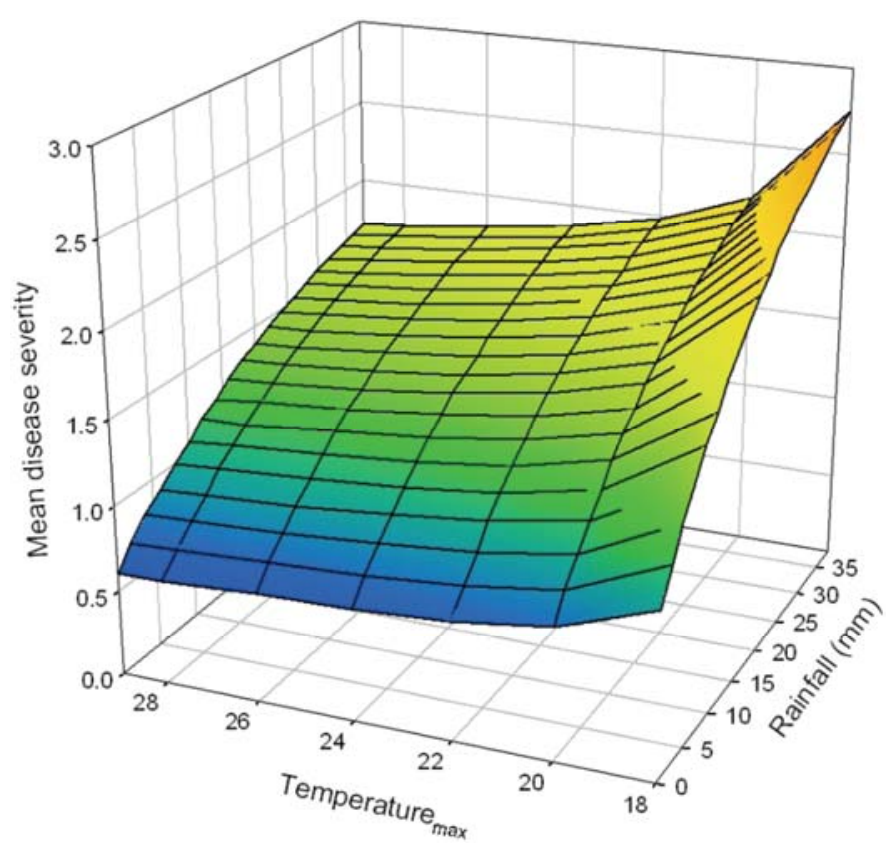

Fig. 3. Response surface for model 2 , disease severity $(D s)=2.65 t^{-0.19}(1-$ $t)^{-0.17} \cdot\{1-[0.7 \exp (-0.04 R)]\}$, describing the influence of total rainfall per week $(R)$ and average maximum temperature per week $\left(T_{\max }\right)$ on the mean blackleg severity of the canola plants infected at six-leaf stage.

Based on this finding, concentration of pycnidiospores on the plants with a higher number of leaves and larger leaf area will be less than those plants with a lower number. This might be the reason that $D s$ in plants infected at the six-leaf stage increased constantly after rainfall exceeded $15 \mathrm{~mm}$ compared with plants at the other two stages.

Parameter $a$ explained the resistance of the plants infected at different growth stages to L. maculans. This parameter was higher in the plants infected at cotyledon stage than plants infected at the other two stages. This can be attributed to the larger size of the plants at six-leaf stage compared with cotyledon stage, because the fungus takes longer to grow from the leaf to the crown in larger plants than in smaller (younger) plants (31); or it may be explained by age-related resistance (ARR), as was observed in Arabidopsis in response to Pseudomonas syringae pv. tomato $(19,32)$

Average maximum temperature also showed a negative relationship with the mean $D s$ of the plants infected at cotyledon and six-leaf stages in both years. $D s$ decreased slightly at $>22$ and $18^{\circ} \mathrm{C}$ for the plants infected at cotyledon and six-leaf stages (except at temperatures between 18 and $20^{\circ} \mathrm{C}$ for plants infected at the six-leaf stage, in which the slope was high). However, no correlation was observed between this weather variable and $D s$ for plants infected at the three-leaf stage. A number of studies showed that the optimum temperature for canker developments (ascospore as main source of inoculum) was at temperatures of 20 to $24^{\circ} \mathrm{C}$ and development of disease decreased at 4 to $8^{\circ} \mathrm{C}$ and did not develop at 28 to $30^{\circ} \mathrm{C}(4,14,23,40)$. Li et al. (22) indicated that crown canker severity of the Australian cultivars inoculated with pycnidiospores of virulent isolates of blackleg at different growth stages under controlled conditions were higher at a temperature regime of 18 and $24^{\circ} \mathrm{C}$ (night and day, respectively) compared with 11 and $18^{\circ} \mathrm{C}$. Also, Sosnowski et al. (36) reported that the greatest number of leaf lesions was observed at a temperature regime of 18 and $15^{\circ} \mathrm{C}$ (day and night) in different Australian cultivars inoculated with pycnidiospores of virulent isolates of blackleg under controlled conditions. They also mentioned that the highest canker development was at a temperature regime of 23 and $20^{\circ} \mathrm{C}$. Vanniasingham and Gilligan (38) showed 


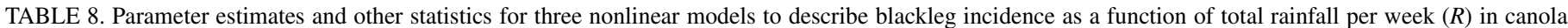
cv. Westar ${ }^{\mathrm{a}}$

\begin{tabular}{|c|c|c|c|c|c|c|c|}
\hline \multirow[b]{2}{*}{ Model } & \multirow[b]{2}{*}{$\mathrm{GS}^{\mathrm{b}}$} & \multirow[b]{2}{*}{ MSE } & \multirow[b]{2}{*}{$R^{2}$} & \multirow[b]{2}{*}{ AIC } & \multicolumn{3}{|c|}{ Estimated parameters $^{\mathrm{c}}$} \\
\hline & & & & & $d_{\max }$ & $B$ & $K$ \\
\hline \multirow[t]{3}{*}{ Monomolecular } & 1,0 & 85.04 & 0.79 & 62.8 & $102.7(5.7)$ & $0.43(0.06)$ & $-0.13(0.06)$ \\
\hline & 1,03 & 187.6 & 0.67 & 73.9 & $94.6(5.6)$ & $0.51(0.10)$ & $-0.25(0.14)$ \\
\hline & 1,06 & 179.1 & 0.77 & 73.3 & $89.8(5.9)$ & $0.66(0.09)$ & $-0.20(0.09)$ \\
\hline \multirow[t]{3}{*}{ Logistic } & 1,0 & 83.2 & 0.80 & 62.5 & $102(4.8)$ & $0.73(0.15)$ & $0.17(0.07)$ \\
\hline & 1,03 & 178.3 & 0.70 & 73.2 & $94.5(4.9)$ & $1.03(0.38)$ & $0.37(0.19)$ \\
\hline & 1,06 & 178.0 & 0.77 & 73.1 & $88.9(5.2)$ & $1.75(0.67)$ & $-0.31(0.15)$ \\
\hline \multirow[t]{3}{*}{ Gompertz } & 1,0 & 82.2 & 0.79 & 62.7 & $102.3(5.2)$ & $0.56(0.06)$ & $-0.15(0.09)$ \\
\hline & 1,03 & 182.4 & 0.68 & 73.5 & $94.5(5.2)$ & $0.71(0.19)$ & $-0.31(0.16)$ \\
\hline & 1,06 & 178.0 & 0.77 & 73.1 & $89.2(5.4)$ & $1.05(0.26)$ & $-0.27(0.12)$ \\
\hline
\end{tabular}

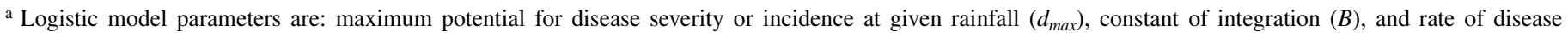
change with respect to increasing moisture factor $(k)$. Mean square error (MSE), pseudo-coefficient of determination $\left(R^{2}\right)$, and Akaike's Information Criterion (AIC) are presented for each model.

${ }^{\mathrm{b}}$ Growth stages: cotyledon stage $(1,0)$, three-leaf stage $(1,03)$, and six-leaf stage $(1,06)$.

${ }^{c}$ Numbers in parentheses correspond to the standard error.

that the optimum temperature for germination of pycnidiospores and production of pycnidia of L. maculans was 20 to $25^{\circ} \mathrm{C}$. In another study, they showed that the rating of pycnidiospore germination at $25^{\circ} \mathrm{C}$ was slightly lower than at $20^{\circ} \mathrm{C}$. The Tmax value for development of $D s$ for plants infected at the six-leaf stage was underestimated. It could partly be explained by the fact that a constant temperature regime was employed in growth cabinets (22) compared with fluctuating temperature under field conditions in our study (Tmax in most warm weeks exceeded $30^{\circ} \mathrm{C}$ ). Nevertheless, underestimation of Tmax for development of $D s$ for plants infected at the six-leaf stage and lack of correlation of this variable with development of $D s$ for plants infected at the three-leaf stage imply that more detailed data sets are needed to precisely evaluate the effect of this variable on the mean $D s$ under field conditions.

$D i$ also correlated with total rainfall per week as expected. For three plant growth stages, $D i$ increased with increase in total rainfall per week. $D i$ then became constant when rainfall reached 20, 15 , and $10 \mathrm{~mm}$ in plants infected at cotyledon, three-leaf, and sixleaf stages, respectively. The upper asymptote of $D i$ of the plants infected at cotyledon stage $(100 \%)$ was higher than of the plants infected at the two other stages. It is interesting that $D i$ is $\approx 60,45$, and $30 \%$ in the plants infected at cotyledon, three-leaf, and sixleaf stages, respectively, before rainfall begins. Constant mean relative humidity (70 to $93 \%$ ) during most weeks in both years which may cause release of pycnidiospore $(13,41)$ and subsequent direct contact of plant leaves with the sources of inoculum (14) could probably explain infection of the plants before rain events.

Introducing a nonlinear weather-based model to predict mean $D s$ and $D i$ under field conditions based on pycnidiospores of $L$. maculans as primary inoculum is an important accomplishment of this research. These models showed that the timing of infection in relation to the growth stage of the plant is an important factor in development of severe stem canker. This study also confirmed the main effect of rainfall in development of disease caused by pycnidiospores of L. maculans. The results of this research could be used to develop a comprehensive model to evaluate epidemics of blackleg based on both ascospores and pycnidiospores as sources of inoculum. Additional years of data collection should improve model fit and evaluation of introduced models and contribute to the development of a more robust predictive model.

\section{ACKNOWLEDGMENTS}

We thank NSERC, Canada and ARDI Manitoba for its financial contributions to carry out the work; and P. Parks and A. Iverson for their assistance in the field.

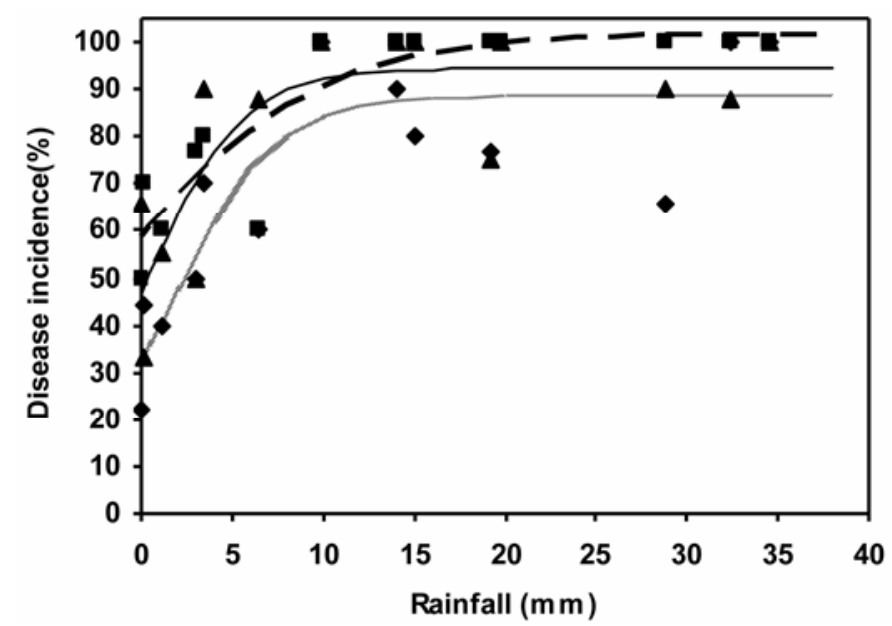

Fig. 4. Models disease incidence $(D i)=f(R)=102\{1+[0.74(\exp [-0.18 R])]\}$, $D i=f(R)=94.45\{1+[1.04(\exp [-0.38 R])]\}$, and $D i=f(R)=88.85\{1+$ $[1.77(\exp [-0.35 R])]\}$, describing the influence of total rainfall per week $(R)$ on the predicted blackleg incidence of canola plants infected at cotyledon (dashed line), three-leaf (solid line), and six-leaf (dotted line) stages. Symbols represent observed mean of blackleg incidence for 15 weeks in 2 years for the plants infected at cotyledon $(\mathbf{\square})$, three-leaf $(\boldsymbol{\Delta})$, and six-leaf $(\bullet)$ stages.

\section{LITERATURE CITED}

1. Aegerter, B. J., Nunez, J. J., and Davis, R. M. 2003. Environmental factors affecting rose downy mildew and development of a forecasting model for a nursery production system. Plant Dis. 87:732-738.

2. Arseniuk, E., and Goral, T. 1998. Seasonal patterns of spore dispersal of Phaeosphaeria spp. and Stagonospora spp. Plant Dis. 82:187-194.

3. Bailey, K. L., Gossen, B. D., Gugel, R. K., and Morrall, R. A. A. 2003. Diseases of field crops in Canada. University Extension Press, Saskatoon, Canada.

4. Barbetti, M. J. 1975. Late blackleg infections in rape are important. Aust. Plant Pathol. Soc. Newsl. 4:3-4.

5. Biddulph, J. E., Fitt, B. D. L., Leech, P. K., Welham, S. J., and Gladders, P. 1999. Effects of temperature and wetness duration on infection of oilseed rape leaves by ascospores of Leptosphaeria maculans (stem canker). Eur. J. Plant Pathol. 105:769-781.

6. Campbell, C., and Madden, L. V. 1990. Introduction to Plant Disease Epidemiology. John Wiley \& Sons, New York.

7. Carisse, O., Bourgeois, G., and Duthie, A. 2000. Influence of temperature and leaf wetness duration on infection of strawberry leaves by Mycosphaerella fragariae. Phytopathology 90:1120-1125.

8. Del Ponte, E. M., Godoy, C. V., Li, X., and Yang, X. B. 2006. Predicting severity of Asian soybean rust epidemics with empirical rainfall models. Phytopathology 96:797-803.

9. Duthie, J. A. 1997. Models of the response of foliar parasites to the combined effects of temperature and duration of wetness. Phytopathology 87:1088-1095.

10. Fitt, B. D. L., Brun, H, Barbetti, M. J., and Rimmer, S. R. 2006. World- 
wide importance of Phoma stems canker (Leptosphaeria maculans and $L$. biglobosa) on oilseed rape (Brassica napus). Eur. J. Plant Pathol. 114:3-15.

11. Ghanbarnia, K. 2008. Modeling blackleg severity and incidence in canola and identification of molecular markers linked to a Leptosphaeria maculans avirulence gene. Ph.D. thesis, University of Manitoba, Winnipeg, Canada.

12. Gladders, P., and Symonds, B. V. 1995. Occurrence of canker (Leptosphaeria maculans) in winter oilseed rape in eastern England 1977-1993. Int. Organ. Biol. Control Bull. 18:1-11.

13. Guo, X. W., and Fernando, W. G. D. 2005. Seasonal and diurnal patterns of spore dispersal by Leptosphaeria maculans from canola stubble in relation to environmental conditions. Plant Dis. 89:97-104.

14. Hall, R. 1992. Epidemiology of blackleg of oilseed rape. Can. J. Plant Pathol. 14: 46-55.

15. Huang, Y. J., Fitt, B. D. L., Jedryczka, M., Dakowska, S., West, J. S., Gladders, P., Steed, J. M., and Li, Z. Q. 2005. Patterns of ascospores release in relation to Phoma stem canker epidemiology in England (Leptosphaeria maculans) and Poland (Leptosphaeria biglobosa). Eur. J. Plant Pathol. 111:263-277.

16. Huang, Y. J., Toscano-Underwood, C., Fitt, B. D. L., Hu, X. J., and Hall, A. M. 2003. Effects of temperature on ascospore germination and penetration of oilseed rape (Brassica napus) leaves by A- or B-group Leptosphaeria maculans (Phoma stem canker). Plant Pathol. 52:245-255.

17. Huang, Y. J., Toscano-Underwood, C., Fitt, B. D. L. Todd, A. D. West, J. S. Koopmann, B., and Balesdent, M. H. 2001. Effects of temperature on germination and hyphal growth from ascospores of A-group and B-group Leptosphaeria maculans (Phoma stem canker of oilseed rape). Ann. Appl. Biol. 139:193-207.

18. Khangura, R., Speijers, J., Barbetti, M. J. Salam, M. U., and Diggle, A. J. 2007. Epidemiology of blackleg (Leptosphaeria maculans) of canola (Brassica napus) in relation to maturation of pseudothecia and discharge of ascospores in Western Australia. Phytopathology 97:1011-1021.

19. Kus, J. V., Zaton, K., Sarkar, R., and Cameron, R. K. 2002. Age-related resistance in Arabidopsis is a developmentally regulated defense response to Pseudomonas syringae. Plant Cell 14:479-490.

20. Kutcher, H. R. 1990. Studies on blackleg disease of oilseed rapes: Germplasm evaluation, variation for virulence, and crop loss/disease relationships. M.Sc. thesis, University of Manitoba, Winnipeg, Canada.

21. Li, H., Sivasithamparam, K., Barbetti, M. J., and Kuo, J. 2004. Germination and invasion by ascospores and pycnidiospores of Leptosphaeria maculans on spring-type Brassica napus canola varieties with varying susceptibility to blackleg. J. Gen. Plant Pathol. 70:261-269.

22. Li, H., Smyth, F., Barbetti, M. J., and Sivasithamparam, K. 2006. Relationship between Brassica napus seedling and adult plant responses to Leptosphaeria maculans is determined by plant growth stage at inoculation and temperature regime. Field Crops Res. 96:428-437.

23. Li, H., Tapper, Nicole, D. N. Barbetti, M., and Sivasithamparam, K. 2006. Enhanced pathogenicity of Leptosphaeria maculans pycnidiospores from paired co-inoculation of Brassica napus cotyledons with ascospores. Ann. Bot. 97:1151-1156.

24. Madden, L. V. 1997. Effects of rain on splash dispersal of fungal pathogens. Can. J. Plant Pathol. 19:225-230.

25. Madden, L. V., Hughes, G., and van den Bosch, F. 2007. The Study of Plant Disease Epidemics. American Phytopathological Society, St. Paul, $\mathrm{MN}$.

26. McGee, D. C., and Emmet, R. W. 1977. Blackleg (Leptosphaeria maculans) of rapeseed in Victoria: crop losses and factors which affects disease severity. Aust. J. Agric. Res. 28:47-51.

27. McGee, D. C., and Petrie, G. A.1979. Seasonal patterns of ascospore discharge by Leptosphaeria maculans in relation to blackleg of oilseed rape. Phytopathology 69:586-589.

28. Mith, K. P. S., Handelsman, J., and Goodman, R. M. 1997. Modeling dose-response relationships in biological control: Partitioning host responses to the pathogen and biocontrol agent. Phytopathology 87:720729.

29. Montesinos, E., and Bonaterra, A. 1996. Dose-response models in biological control of plant pathogens: an empirical verification. Phytopathology $86: 464-472$

30. Peres, A., and Poisson, B. 1997. Phoma du colza: Avencees en epidemiologie. CETIOM-Oleoscope 40:37-40.

31. Petrie, G. A. 1995. Patterns of ascospore discharge by Leptosphaeria maculans (blackleg) from 9- to 13-month-old naturally-infected rapeseed/canola stubble from 1977 to 1993 in Saskatchewan. Can. Plant Dis. Surv. 75:35-43.

32. Rusterucci, C., Zhao, Z., Haines, K., Mellersh, D., Neumann, A., and Cameron, R. K. 2005. Age-related resistance to Pseudomonas syringae pv. tomato is associated with the transition to flowering in Arabidopsis and is effective against Peronospora parasitica. Physiol. Mol. Plant Pathol. 66:222-231.

33. Salam, M. U., Fitt, B. D. L., Aubertot, J. N., Diggle, A. J., Huang, Y. J., Barbetti, M. J., Gladders, P., Jedryczka, M., Khangura, R. K., Wratten, N., Fernando, W. G. D., Pinochet, X., Penaud, A., and Sivasithamparam, K. 2007. Two weather-based models for predicting onset of seasonal release of ascospores of Leptosphaeria maculans. Plant Pathol. 56:412-423.

34. Salam, M. U., Khangura, R. K., Diggle, A. J., and Barbetti. M. J. 2003. Blackleg sporacle: a model for predicting onset of pseudothecia maturity and seasonal ascospore showers in relationship to blackleg of canola. Phytopathology 93:1073-1081.

35. Shoemaker, R. A., and Burn, H. 2001. The teleomorph of the weakly aggressive segregate of Leptosphaeria maculans. Can. J. Bot. 79:412-419.

36. Sosnowski, M. R., Scott, E. S., and M. D. Ramsey. M. D. 2005. Temperature, wetness period and inoculum concentration influence infection of canola (Brassica napus) by pycnidiospores of Leptosphaeria maculans. Aust. Plant Pathol. 34:339-344.

37. Travadon, R., Bousset, L., Saint-Jean, S., and Sache, I. 2007. Splash dispersal of Leptosphaeria maculans pycnidiospores and the spread of blackleg on oilseed rape. Plant Pathol. 56:595-603.

38. Vanniasingham, V. M., and Gilligan, C. A. 1988. Effects of biotic and abiotic factors on germination of pycnidiospores of Leptosphaeria maculans in vitro. Trans. Br. Mycol. Soc. 90:415-420.

39. Vanniasingham, V. M., and Gilligan, C. A. 1989. Effects of host, pathogen and environmental factors on latent period and production of pycnidia of Leptosphaeria maculans on oilseed rape leaves in controlled environments. Mycol. Res. 93:167-174.

40. West, J. S., Biddulph, J. E., Fitt, B. D. L., and Gladders, P. 1999. Epidemiology of Leptosphaeria maculans in relation to forecasting stem canker severity on winter oilseed rape in the UK. Ann. Appl. Biol. 135:535-546.

41. West, J. S., Kharbanda, P. D. Barbetti, M. J., and Fitt, B. D. L. 2001. Epidemiology and management of Leptosphaeria maculans (Phoma stem canker) on oilseed rape in Australia, Canada and Europe. Plant Pathol. 50:0-27.

42. Williams, P. H. 1992. Biology of Leptosphaeria maculans. Can. J. Plant Pathol. 14:30-35.

43. Wood, P. M., and Barbetti, M. J. 1977. A study on the inoculation of rape seedlings with ascospores and pycnidiospores of the blackleg disease causal agent. J. Aust. Inst. Agric. Sci. 43:79-80.

44. Wu, L., Damicone, J. P., Duthie, J. A., and Melouk, H. A. 1999. Effects of temperature and wetness duration on infection of peanut cultivars by Cercospora arachidicola. Phytopathology 89:653-659. 